\title{
PHARMACOKINETIC EVALUATION OF A CHRONOTHERAPEUTIC SYSTEM LOADED WITH AN ANTIASTHMATIC DRUG AS AN ORAL DRUG DELIVERY SYSTEM \\ BY
}

\author{
Rasha S.E. Elbatanony ${ }^{\mathrm{a},}$, Seham A. Elkheshen ${ }^{\mathrm{a}, \mathrm{b}}$, \\ FROM \\ ${ }^{\text {a }}$ Department of Pharmaceutics and Pharmaceutical Technology, Faculty of \\ Pharmaceutical Sciences and Pharmaceutical Industries, Future University in Egypt, \\ Cairo, Egypt. \\ ${ }^{\mathrm{b}}$ Department of Pharmaceutics and Industrial Pharmacy, Faculty of Pharmacy, Cairo \\ University, Cairo, Egypt.
}

\begin{abstract}
Recent studies proved that the symptoms of bronchial asthma follow the circadian rhythms and become worse in the early morning. In such cases, conventional sustained-release treatment regimens are inappropriate for the delivery of antiasthmatic drugs as they cannot be administrated just prior to the worsening of the symptoms. The current work aimed to explore the pharmacokinetics of a model antiasthmatic drug following oral administration of a chronotherapeutic system in six healthy volunteers. A sensitive and selective chromatoghraphic method was used to determine drug concentration in human plasma. A standard calibration curve of the drug over the concentration range of $0.15-80 \mu \mathrm{g} / \mathrm{ml}$ was prepared in human plasma. Anhydrous caffeine was used as an internal standard. The protocol of the studies was approved by the Research Ethics Committee for clinical studies at Faculty of Pharmacy, Cairo University, Egypt. Following oral administration of the treatments, the pharmacokinetic parameters of the drug including $\mathrm{C}_{\max }(\mu \mathrm{g} / \mathrm{ml}), \mathrm{T}_{\max }(\mathrm{h}), \mathrm{MRT}_{(0-\infty)}$, (h), $\mathrm{AUC}_{0-24}$ $(\mu \mathrm{g} \mathrm{h} / \mathrm{ml})$ and $\mathrm{AUC}_{0-\infty}(\mu \mathrm{g} \mathrm{h} / \mathrm{ml})$ were derived from the individual plasma concentration time curves. The data were statistically analyzed using two-way ANOVA at $P<0.05$. The results confirmed that the drug reached $C_{\max }$ rapidly within two hours following a definite lag time; confirming the potential of the developed chronotherapeutic system in promoting the drug absorption at its site of action at the required time.
\end{abstract}

Keywords: antiasthmatic drug, circadian rhythm, pharmacokinetics, pulsatile drug delivery system.

\section{Introduction}

After several experiments in animals and in humans, scientists have clearly demonstrated that people vary considerably in their physiological and biochemical conditions due to the circadian rhythm. These predictable temporal cycles not only affect different physiological functions, like blood pressure or heart rate, but also can influence the pharmacokinetic phases of drugs (De Giorgi et al 2013, Baraldo 2008). In view of the aforementioned, the traditional delivery systems that promote constant delivery of the drug into the body seem unnecessary and/or undesirable. Instead, the drug release profile should be tailored to mimic a living system's pulsatile hormone 
secretion, so that the drug efficacy could be improved and the possible toxicity of a specific drug regimen might be reduced (Ashwini et al 2012

Asim et al 2010 and Gandhi et al 2011). The latter approach can be addressed by chronopharmaceutical drug delivery systems which exhibit pulsatile drug release profiles that coincide with the circadian rhythms ${ }^{6}$ (Youan 2004).

Oral pulsatile drug delivery systems are designed to elicit programmable lag periods preceding (i) prompt, (ii) repeated or (iii) sustained release of drugs. These systems show inherent suitability for accomplishing chronotherapeutic goals, which have recently been interconnected with many chronic diseases with typical night or early morning recurrence of symptoms like bronchial asthma, cardiovascular disease or rheumatoid arthritis. In fact, the un-interrupted normal sleep patterns would be expected to ensure higher compliance (Maroni et al 2010, Ali et al 2010 and Ingersoll et al 2014).

A variety of design strategies have been attempted for pulsatile release purposes; including; solid lipid microparticles (Albertini et al 2014), pellets (Zhang et al 2014), osmotically-controlled capsules (Ranjan et al 2014), membrane rupture systems (Lin et al 2008), time-controlled explosion systems (Ueda et al 1994), tabs-in-cap systems (Gangwar et al 2015), mini-tablets (Biswas et al 2014), press coated tablets (Shah et al 2015), Chronotropic systems (Gazzaniga et al 1994) and core-in-cup dry coated tablets (Efentakis et al 2011, Efentakis et al 2006).

Most of these systems allowed the release of the loaded-drug over a prolonged period of time following a definite lag period.

In the current work, the in vivo pharmacokinetic parameters of a model antiasthmatic drug following oral administration of a chronotherapeutic system were estimated in healthy volunteers to explore the ability of this system to allow a prompt drug release following a definite lag period.

\section{Materials and Methods}

\subsection{Materials}

Theophylline (TE) was granted by FIS Fabrica Italiana Sintetici, (Alto de Montevecchio, Italy). Ethoce ${ }^{\circledR}$ Standard 100 Premium FP (ethyl cellulose) was donated by Dow Chemical Company (Midland, MI, USA). Methocel ${ }^{\circledR}$ E5 (HPMC 2910) and Methocel ${ }^{\circledR}$ K100M Premium (HPMC 2208) were grant samples from Colorcon Ltd. (Orpington, UK). Magnesium stearate was purchased from Herwe Chemisch-technische Erzeugnisse GmbH (Sinsheim-Dühren, Germany).

Acetonitrile (HPLC grade), methanol (HPLC grade), tetrahydrofuran (HPLC grade) were purchased from Sigma Chemical Co. (St. Louis, USA). Caffeine hydrochloride (CA; an internal standard) was provided by Pharco Pharmaceuticals (Alexandria, Egypt).

\subsection{Establishment of a standard calibration curve of $\mathrm{TE}$ in human plasma}

A stock solution of TE in methanol $(20 \mu \mathrm{g} / \mathrm{ml})$ was prepared. Another stock solution of CA (internal standard) in a 1:1 mixture of acetonitrile - methanol $(5 \mu \mathrm{g} / \mathrm{ml})$ was prepared. For the preparation of the calibration curve, blank plasma samples were spiked with TE to contain $0.15-80 \mu \mathrm{g} / \mathrm{ml}$. Aliquots of spiked plasma samples $(100 \mu \mathrm{l})$ were mixed with caffeine hydrochloride stock solution $(200 \mu \mathrm{l})$ and the mixtures were vortexed for $30 \mathrm{sec}$ and centrifuged at $8000 \mathrm{x} \mathrm{g}$ for $10 \mathrm{~min}$. Portions of the supernatants 
were transferred to HPLC tubes and then injected onto the Ultra performance liquid chromatography column. A standard curve was constructed by plotting the peak-area ratios of TE / CA against TE concentrations in human plasma. All assays were performed in triplicate. The lower limit of quantification was $0.15 \mu \mathrm{g} / \mathrm{ml}$. The procedural constant $(\mathrm{K})$ was calculated from the slope of each calibration curve.

\subsection{In vivo absorption studies in healthy volunteers}

\subsubsection{Study design}

The in vivo studies followed a two-treatment, two-period, randomized, crossover design to assess the pharmacokinetics of TE following oral administration of sustained release marketed tablets (Treatment $\mathrm{A}$, the reference product) and the chronotherapeutic system (Treatment B) at single $100 \mathrm{mg}$ doses of TE. The protocol of the studies was approved by the Research Ethics Committee for clinical studies at Faculty of Pharmacy, Cairo University, Egypt. The studies were conducted in full compliance with the declarations of Helsinki and Tokyo for human volunteers.

\subsubsection{Subjects}

The studies involved six healthy, non-smoking, male volunteers with no history of alcohol- or drug-abuse problems. The subjects had appropriate measures; varied in weight from 64 to $82 \mathrm{~kg}(73.5 \mathrm{~kg})$, in age from 22 and 35 years $(28.5$ year), and in height from 166 to $188 \mathrm{~cm}(177.5 \mathrm{~cm})$. A general practitioner reviewed the medical history of each volunteer and conducted a general physical examination to confirm the appropriate participation in the studies. Furthermore, the necessary hematological laboratory evaluations (total cholesterol, plasma glucose, blood urea, serum creatinine, SGOT and SGPT, hemoglobin concentration, RBC, Total Leukocyte and Platelet counts) were screened. All volunteers were instructed not to use any medicines, vitamin or herbal supplement from one week before and until the end of the studies. Following the full explanation of the nature and the purpose of the study, an informed written consent was obtained from each volunteer.

\subsubsection{Administration of treatments and processing of samples}

The subjects were randomly assigned to one of two groups of equal number. On phase I of the study, half the number of volunteers received one-third of oral sustained release marketed tablets $300 \mathrm{mg}$ (Treatment A) while the other half of volunteers received the chronotherapeutic system (Treatment B) composed of TE $(10 \% \mathrm{w} / \mathrm{w})$, Ludipress $®(30 \% \mathrm{w} / \mathrm{w})$ in core and outer coat consisting of Methocel ${ }^{\circledR}(30 \% \mathrm{w} / \mathrm{w})$ and ethylcellulose $(30 \% \mathrm{w} / \mathrm{w})$. According to FDA regulations, both treatments were ingested with $200 \mathrm{ml}$ of water after 12-h overnight fasting. It should be noted that, no water was allowed one hour prior to drug administration. Yet, water was re-permitted two hours post dosing. Food and other drinks were permitted for $4 \mathrm{~h}$ post dosing.

Following a washout period of one week, the reverse of randomization took place on phase II. In both phases, venous blood samples $(5 \mathrm{ml})$ derived from the forearm cubital veins were collected into heparinized tubes, prior to and up to $24 \mathrm{~h}$ post administration of treatments. The plasma samples were derived by centrifugation at $4000 \times \mathrm{g}$ for $10 \mathrm{~min}$ and then pipetted into well-defined glass tubes (labeled with the run date, the subject code, the study period, the treatment type; reference or test) and finally frozen at $-20^{\circ} \mathrm{C}$ until analysis. 
The thawed plasma samples $(100 \mu \mathrm{l})$ were spiked with caffeine hydrochloride (CA) internal standard solution in a 1:1 mixture of acetonitrile - methanol $(200 \mu \mathrm{L} ; 5$ $\mu \mathrm{g} / \mathrm{ml}$ ) and treated as previously reported to precipitate the plasma proteins.

\subsubsection{Determination of $\mathrm{TE}$ concentration in human plasma by Ultra performance liquid chromatography}

A sensitive and specific Ultra performance liquid chromatographic method was adopted for the quantitative determination of TE in human plasma. The mobile phase consisted of a mixture of tetrahydrofuran $(30 \%, \mathrm{v} / \mathrm{v})$ : acetonitrile: water (10: 10: 80). It eluted through Epitomize ${ }^{\mathrm{TM}}$ Chiral CSP1 column $(3.0 \times 50 \mathrm{~mm})$ packed with $1.7 \mu \mathrm{m}$ particles (Orochem Technologies, Inc., IL, USA) at a flow rate of $0.5 \mathrm{ml} / \mathrm{min}$. The peak areas of TE and CA were recorded.

\subsection{5 . Pharmacokinetic and statistical analyses of data}

The pharmacokinetic parameters for THE following oral administration of both treatments were determined by means of WinNonlin ${ }^{\circledR}$ software adopting the noncompartmental module. The maximum drug concentration $\left(\mathrm{C}_{\max }, \mu \mathrm{g} / \mathrm{ml}\right)$, the time to reach $C_{\max }\left(T_{\max }, h\right)$, the mean residence time from zero to infinity $\left(\mathrm{MRT}_{0-\infty}, \mathrm{h}\right)$, the area under the plasma concentration-time curve up to 24 hour (AUC ${ }_{0-24}, \mu \mathrm{g} \mathrm{h} / \mathrm{ml}$ ) and upto infinity $\mathrm{AUC}_{0-\infty}(\mu \mathrm{g} \mathrm{h} / \mathrm{ml})$ were determined.

The primary pharmacokinetic parameters including $\mathrm{C}_{\max }, \mathrm{AUC}_{(0-24)}$ and $\mathrm{AUC}_{(0-}$ $\infty)$ were statistically analyzed, at $P<0.05$, using two-way ANOVA.

\section{Results and discussion}

\subsection{Linearity of the standard curve of theophylline $\mathrm{HCl}$}

Figure 1 shows the chromatogram of TE and CA internal standard solution in a 1:1 mixture of acetonitrile - methanol $(200 \mu \mathrm{L} ; 5 \mu \mathrm{g} / \mathrm{ml})$ in plasma. The peaks of both components were sharp and symmetrical with good base line resolution. The retention time of TE was 0.74 min while that of CA was 1.04 min. The correlation between TE / CA peak area ratio and TE concentration in plasma is shown in Figure 2. The standard curve showed good linearity over a concentration range of $0.15-80 \mu \mathrm{g} / \mathrm{ml}$. The lower limit of quantification (LLOQ) that represents a signal: noise ratio of $10: 1$ was found to be $0.15 \mu \mathrm{g} / \mathrm{ml}$. The linear regression equation was found to be:

$$
\mathrm{y}=0.0967 \mathrm{x}+0.0367
$$

Where $\mathrm{y}$ is [TE / CA peak area ratio and $\mathrm{x}$ is THE concentration in $\mu \mathrm{g} / \mathrm{ml}$. K was found to be 10.341 


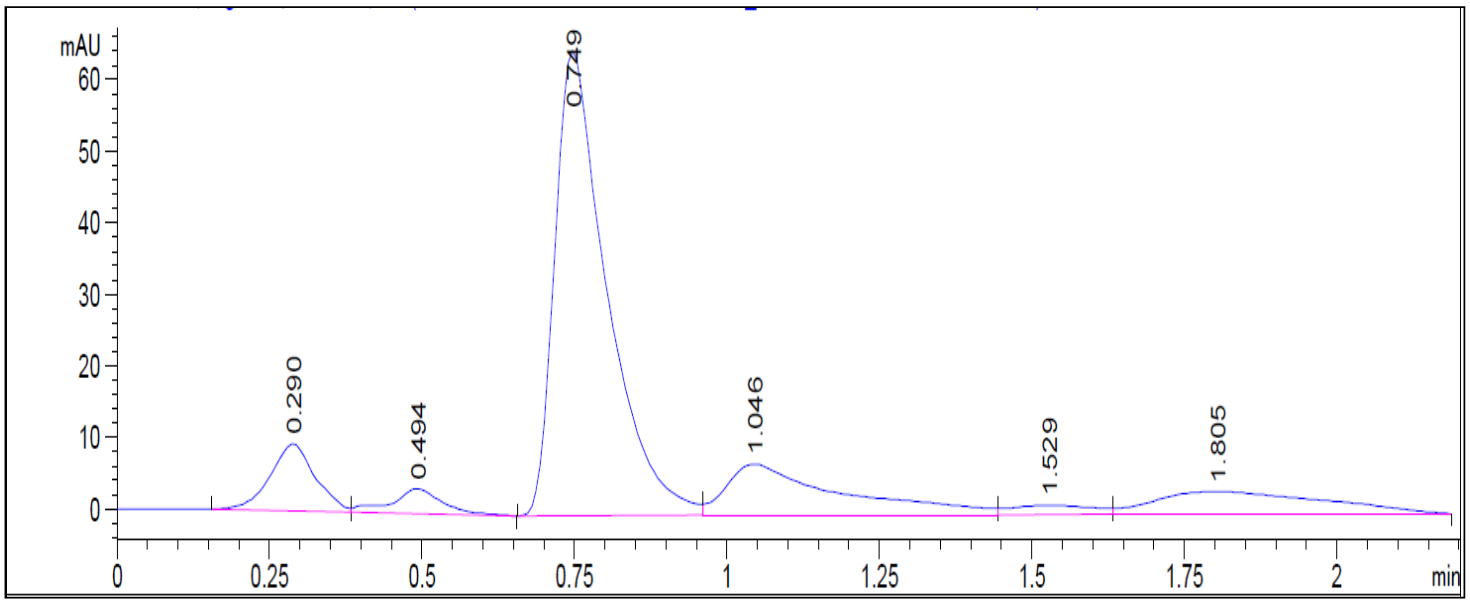

Fig. 1 A representative chromatogram of $\mathrm{TE}$ and $\mathrm{CF}$ in human plasma.

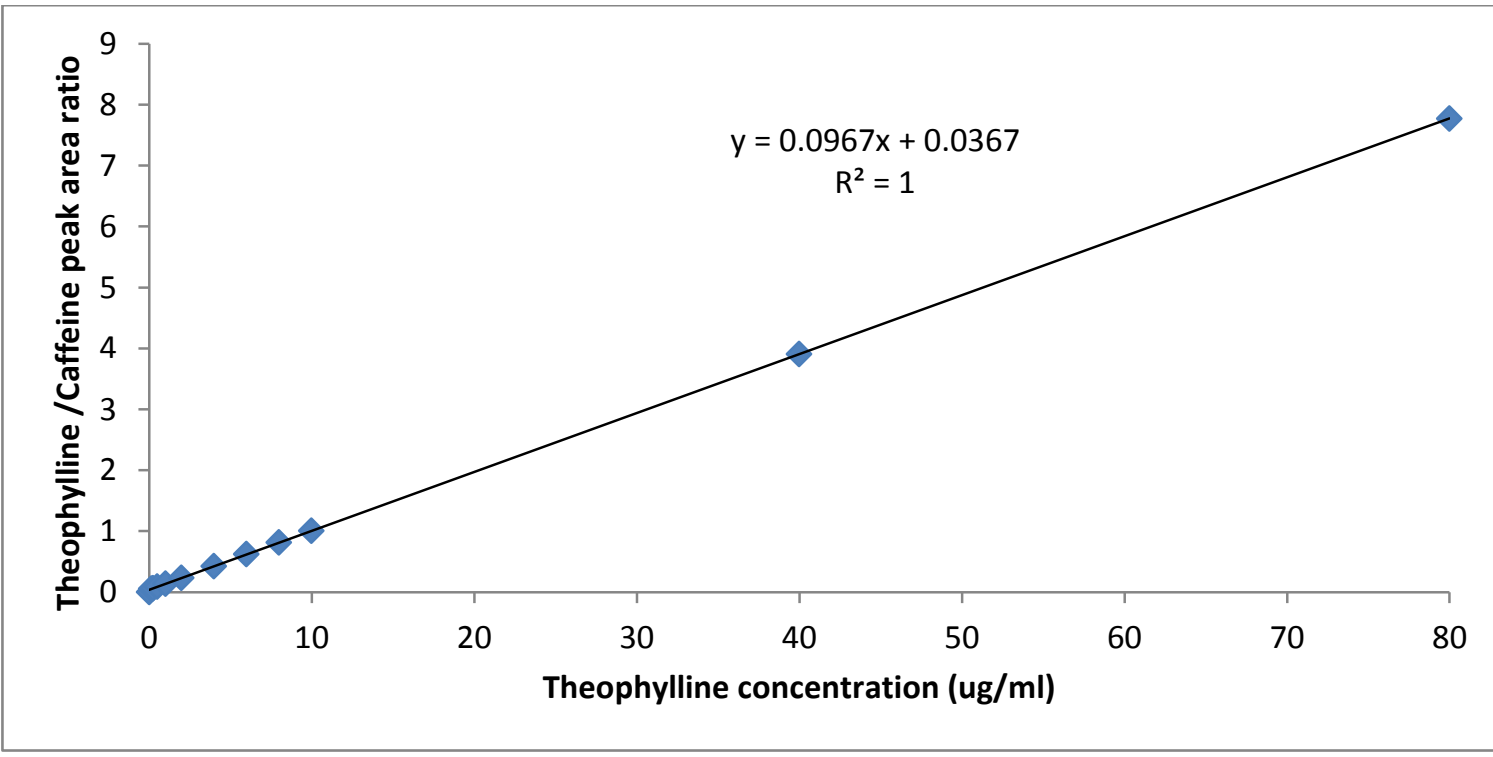

Fig. 2 The correlation between TE / CF peak area ratio and TE concentration in plasma.

\subsection{In vivo absorption studies in healthy volunteers}

The plasma concentrations of THE following oral administration of oral sustained release marketed tablets (treatment A) and TE-loaded chronotherapeutic system (treatment B) in healthy volunteers at $100 \mathrm{mg}$ doses are displayed Tables $(1-2)$ and Fig. 3. The pharmacokinetic parameters $\left[\mathrm{C}_{\max }, \mathrm{T}_{\max }, \mathrm{MRT}_{0-\infty}, \mathrm{AUC}_{0-24}\right.$ and $\mathrm{AUC}_{0-}$ ${ }_{\infty}$ ] were derived by the non-compartmental fitting of data and are summarized in Table (3). 
Table 1 TE plasma concentrations $(\mu \mathrm{g} / \mathrm{ml})$ following oral administration of Treatment A to six healthy volunteers

\begin{tabular}{|c|c|c|c|c|c|c|c|}
\hline \multirow{2}{*}{ Time (h) } & \multicolumn{7}{|c|}{ Volunteer number } \\
\cline { 2 - 7 } & 1 & 2 & 3 & 4 & 5 & 6 & Mean \pm S.D. \\
\hline 0 & 1.31 & 1.95 & 0.10 & 0.80 & 1.31 & 1.84 & $1.04 \pm 0.88$ \\
\hline 0.5 & 3.68 & 2.38 & 0.79 & 1.71 & 3.68 & 3.01 & $2.14 \pm 1.10$ \\
\hline 1 & 4.43 & 3.70 & 1.26 & 1.48 & 4.43 & 3.70 & $2.72 \pm 1.88$ \\
\hline 2 & 8.17 & 7.67 & 4.79 & 9.44 & 8.17 & 1.30 & $7.51 \pm 3.83$ \\
\hline 4 & 6.82 & 7.82 & 7.06 & 6.00 & 6.82 & BQL & $6.92 \pm 2.96$ \\
\hline 5 & 5.64 & 7.17 & 6.53 & 4.79 & 5.64 & BQL & $6.07 \pm 2.66$ \\
\hline 6 & 5.03 & 5.75 & 5.07 & 4.76 & 5.03 & BQL & $5.15 \pm 2.06$ \\
\hline 8 & 2.92 & 4.38 & 4.12 & 2.53 & 2.92 & 1.73 & $3.49 \pm 1.58$ \\
\hline 9 & 1.32 & 2.38 & 3.49 & 0.58 & 1.32 & 1.60 & $1.94 \pm 1.14$ \\
\hline 12 & 1.41 & 1.40 & 0.83 & 0.36 & 1.41 & 0.29 & $1.00 \pm 1.5$ \\
\hline 24 & 0.72 & 1.08 & 0.01 & 0.52 & BQL & 0.43 & $0.52 \pm 0.42$ \\
\hline
\end{tabular}

$* \mathrm{BQL}=$ below quantification limit

Table 2 TE plasma concentrations $(\mu \mathrm{g} / \mathrm{ml})$ following oral administration of Treatment $B$ to six healthy volunteers

\begin{tabular}{|c|c|c|c|c|c|c|c|}
\hline \multirow{2}{*}{ Time (h) } & \multicolumn{7}{|c|}{ Volunteer number } \\
\cline { 2 - 7 } & 1 & 2 & 3 & 4 & 5 & 6 & Mean \pm S.D. \\
\hline 0 & 0.17 & 1.83 & 0.36 & 0.13 & 0.37 & BQL & $0.57 \pm 0.78$ \\
\hline 0.5 & 0.08 & 4.07 & 0.16 & 0.19 & 0.47 & BQL & $0.99 \pm 1.90$ \\
\hline 1 & 0.11 & 2.51 & 0.31 & 0.62 & 1.07 & BQL & $0.92 \pm 0.97$ \\
\hline 2 & 0.21 & 1.44 & 0.08 & 0.23 & 0.61 & BQL & $0.52 \pm 0.61$ \\
\hline 4 & 1.12 & 1.11 & BQL & 0.13 & 1.15 & BQL & $1.33 \pm 0.92$ \\
\hline 5 & 0.98 & 0.04 & 0.19 & 0.06 & 0.61 & BQL & $0.88 \pm 0.5$ \\
\hline 6 & BQL & 7.60 & 0.40 & 0.39 & 2.80 & BQL & $2.80 \pm 3.40$ \\
\hline 8 & 0.13 & 0.61 & 1.07 & 0.80 & 0.02 & BQL & $0.52 \pm 0.44$ \\
\hline 9 & 4.50 & 0.38 & 0.42 & 1.24 & 0.33 & BQL & $1.38 \pm 0.43$ \\
\hline 12 & 0.10 & 0.45 & 0.10 & BQL & 1.24 & BQL & $0.47 \pm 0.54$ \\
\hline 24 & 0.35 & 0.18 & 0.00 & 0.19 & 0.62 & BQL & $0.27 \pm 0.26$ \\
\hline
\end{tabular}

$* \mathrm{BQL}=$ below quantification limit 
Table 3 The pharmacokinetic parameters for TE following oral administration of both treatments (mean $\pm \mathrm{SD}, \mathrm{n}=6$ ).

\begin{tabular}{|c|c|c|c|c|c|}
\hline Treatment & $\begin{array}{c}\text { Cmax } \\
(\mathrm{ug} / \mathrm{ml})\end{array}$ & $\begin{array}{c}\text { Tmax* } \\
(\mathrm{h})\end{array}$ & $\begin{array}{c}\text { MRT (0- }) \\
(\mathrm{h})\end{array}$ & $\begin{array}{c}\text { AUC (0-24) } \\
(\text { ug.h/ml) }\end{array}$ & $\begin{array}{c}\text { AUC (0- } \infty) \\
(\text { ug.h /ml) }\end{array}$ \\
\hline A & $6.07 \pm 3.3$ & $2 \pm 1.47$ & $9.52 \pm 3.63$ & $42.62 \pm 24.81$ & $48.12 \pm 29.31$ \\
\hline B & $3.44 \pm 2.71$ & $8 \pm 1.52$ & $10.82 \pm 2.75$ & $18.6 \pm 6.51$ & $19.90 \pm 7.19$ \\
\hline
\end{tabular}

*median, mean \pm S.D., $\mathrm{n}=6$

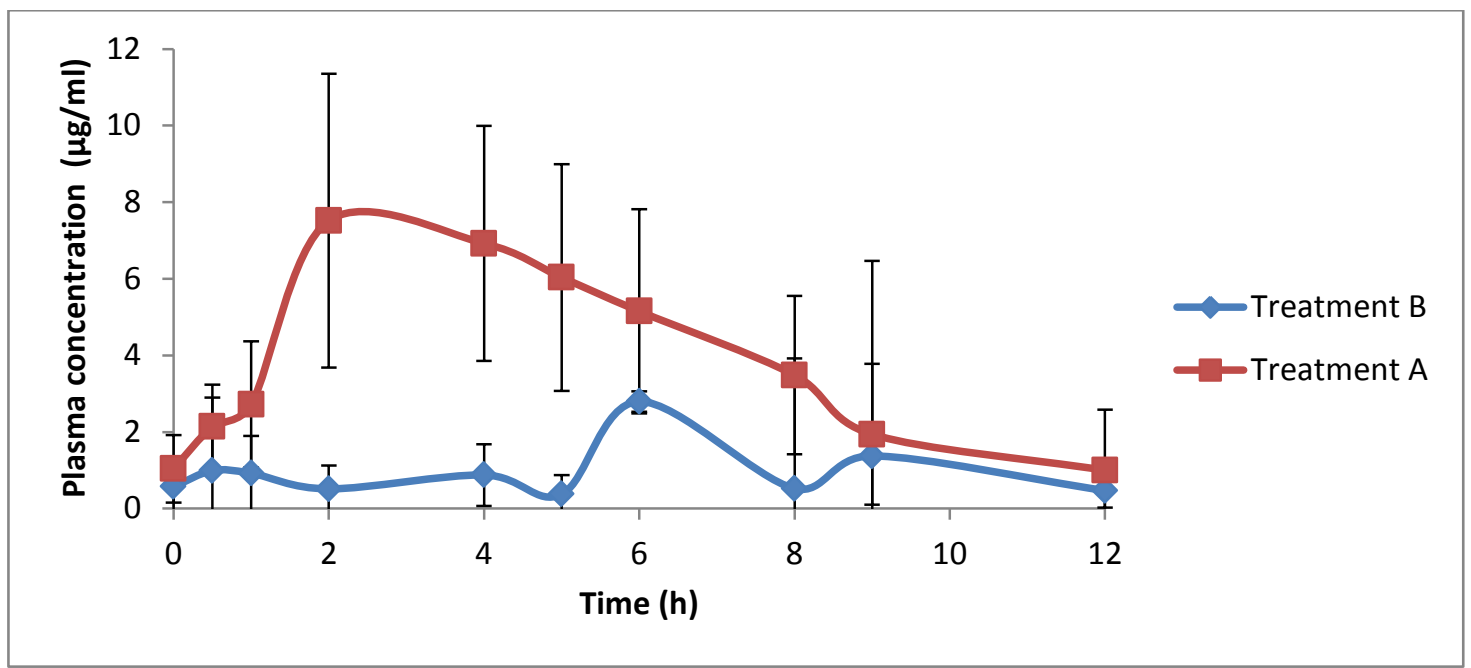

Fig. 3 Plasma concentration- time curves of TE and marketed product after oral administration of marketed product (treatment A) and prepared formulation (treatment B)

Needless to say, marketed product tablets represent a sustained release dosage form. Yet, the designed chronotherapeutic system displayed a pulsatile drug release pattern.

The maximum drug concentration $\left(\mathrm{C}_{\max } ; 6.07 \mathrm{ug} / \mathrm{ml}\right)$ of oral sustained release marketed tablets was achieved at a median $\mathrm{T}_{\max }$ of $2 \mathrm{~h}$. A lower $\mathrm{C}_{\max }$ value $(3.44 \mathrm{ug} / \mathrm{ml})$ was estimated at a median $\mathrm{T}_{\max }$ of $8 \mathrm{~h}$ for the designed chronotherapeutic system. The analysis of these values revealed statistically significant differences at $P<0.05$. Following a $T_{L}$ of 6 hours, TE was completely released within two hours. The prompt pulsatile delivery of TE could be concluded.

It is worth to note that no significant differences $(P>0.05)$ were observed between $\mathrm{AUC}_{0-\infty}$ values of both treatments.

\section{Conclusions}

This study confirms that the developed system promoted the pulsatile delivery of a sparingly-soluble model drug without affecting the extent of its absorption. Further studies are necessary to evaluate the potential of this pulsatile system for water soluble and practically insoluble drugs. 


\section{Acknowledgments}

The authors would like to thank Prof. Ronald Bodmeier (Dean, Free University of Berlin) and Dr. Mina Ibrahim Tadros, Ph.D. (Associate Prof. of Pharmaceutics and Industrial Pharmacy, Faculty of Pharmacy, Cairo University, Egypt).

\section{REFERENCES}

Albertini B, Di Sabatino M, Melegari C, Passerini N. (2014). Int J Pharm; Formulating SLMs as oral pulsatile system for potential delivery of melatonin to pediatric population. 469(1):67-79.

Ali J., Saigal N., Qureshi M.J., Baboota S., Ahuja A. (2010). Recent Pat Drug Deliv Formul; Chronopharmaceutics: : a promising drug delivery finding of the last two decades. 4(2):129-44.

Ashwini R, Bushetti SS, Archana G. (2012). Int J Pharm Pharm Sci; Formulation and Evaluation of compression coated tablets based on modified okra mucilage. 4:660-67.

Asim SM, Nikhil B, Kazi MK, Arijit G, Sugata C, Mamata B. (2010). J Control Release; Drug delivery system based on chronobiology - A review. 147:31425.

Baraldo M. (2008). Expert Opin Drug Metab Toxicol; The influence of circadian rhythms on the kinetics of drugs in humans. 4(2):175-92.

Biswas N, Sahoo RK, Guha A, Kuotsu K. (2014). Int J Biol Macromol; Chronotherapeutic delivery of hydroxypropylmethylcellulose based minitablets: an in vitro-in vivo correlation. 66:179-85.

De Giorgi A, Mallozzi Menegatti A, Fabbian F, Portaluppi F, Manfredini R. (2013). Eur J Intern Med; Circadian rhythms and medical diseases: Does it matter when drugs are taken? 24(8):698-706.

Efentakis M., Koligliati S., Vlachou. M. (2006). Int J Pharm. ., Design and evaluation of a dry coated drug delivery system with an impermeable cup, swellable top layer and pulsatile release. 311(1-2),147-56.

Efentakis M., Iliopoyloy A., Siamidi A. (2011). Drug Dev. Ind. Pharm; Effect of core size and excipients on the lag time and drug release from a pulsatile drug delivery system. 37(1),113-120.

Gandhi BR, Mundada AS, Gandhi PP. (2011). Drug Deliv; Chronopharmaceutics: as a clinically relevant drug delivery system. 18:1-18.

Gangwar G, Kumar A, Pathak K. (2015). Int J Biol Macromol; Utilizing guar gum for development of "tabs in cap' system of losartan potassium for chronotherapeutics. 72:812-8.

Gazzaniga A, Sangalli ME, Giordano F. (1994). Eur J Biopharm; Oral Chronotropic ${ }^{\circledR}$ drug delivery systems: achievement of time and/or site specificity. 40:246-50.

Ingersoll KS, Cohen J. (2008). J Behav Med; The impact of medication regimen factors on adherence to chronic treatment: a review of literature. 31:213-24. 
Lin HL, Lin SY, Lin YK, Ho HO, Lo YW, Sheu MT. (2008). Eur J Pharm Biopharm; Release characteristics and in vitro-in vivo correlation of pulsatile pattern for a pulsatile drug delivery system activated by membrane rupture via osmotic pressure and swelling. 70(1):289-301.

Maroni A, Zema L, Del Curto MD, Loreti G, Gazzaniga A. (2010). Int J Pharm.; Oral pulsatile delivery: Rationale and chronopharmaceutical formulations. 398(1-2):1-8.

Ranjan OP, Nayak UY, Reddy MS, Dengale SJ, Musmade PB, Udupa N. (2014). Drug Deliv; Osmotically controlled pulsatile release capsule of montelukast sodium for chronotherapy: statistical optimization, in vitro and in vivo evaluation. 21(7):509-18.

Shah S, Patel R, Soniwala M, Chavda J. (2015). Drug Dev Ind Pharm; Development and optimization of press coated tablets of release engineered valsartan for pulsatile delivery. 41(11):1835-46.

Ueda S, Ibuki R, Kawamura A, Murata S, Takahashi T, Kimura S, Hata T. (1994). J Drug Target; Development of a novel drug delivery system, time-controlled explosion system (TES). IV. In vivo drug release behavior. 2(2):133-40.

Youan BB. (2004). J Control Release; Chronopharmaceutics: gimmick or clinically relevant approach to drug delivery. 98:337-53.

Zhang Z, Qi X, Li X, Xing J, Zhu X, Wu Z. (2014). Int J Pharm; A novel pulsatile drug delivery system based on the physiochemical reaction between acrylic copolymer and organic acid: in vitro and in vivo evaluation. 462(1-2):66-73.

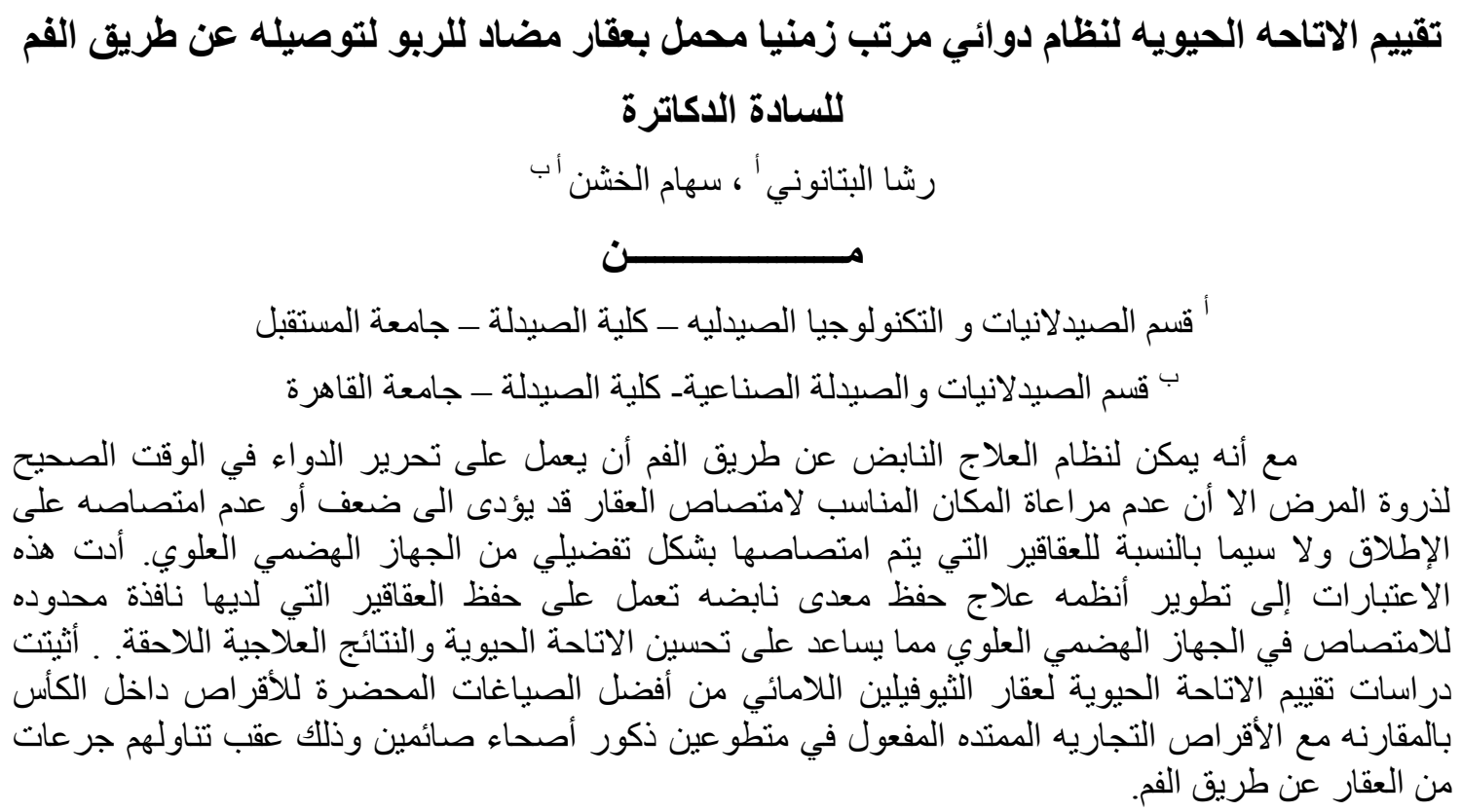

